\title{
IL-37 Causes Excessive Inflammation and Tissue Damage in Murine Pneumococcal Pneumonia
}

\author{
Anja E. Schauer ${ }^{a}$ Tilman E. Klassert ${ }^{a}$ Carolin von Lachner ${ }^{a}$ \\ Diana Riebold $^{b}$ Anne Schneeweiss ${ }^{a}$ Magdalena Stock ${ }^{a}$ Mario M. Müller ${ }^{a}$ \\ Sven Hammerschmidt ${ }^{c}$ Philip Bufler ${ }^{d} \quad$ Ulrike Seifert $^{\mathrm{e}}$ Kristina Dietert ${ }^{f}$ \\ Charles A. Dinarelloi,j Marcel F. Nold ${ }^{\mathrm{g}, \mathrm{h}}$ Achim D. Gruber ${ }^{f}$ \\ Claudia A. Nold-Petryg, h Hortense Slevogt $^{\mathrm{a}}$
}

\begin{abstract}
a Septomics Research Center, Jena University Hospital, and b InfectoGnostics Research Campus Jena, Centre for Applied Research Jena, Jena, 'Department of Genetics of Microorganisms, Interfaculty Institute for Genetics and Functional Genomics, Ernst Moritz Arndt University of Greifswald, Greifswald, dDepartment of Pediatrics, Dr. von Hauner Children's Hospital, Ludwig-Maximilians-University, Munich, e Friedrich Loeffler Institute of Medical Microbiology, University Medicine Greifswald, Greifswald, and Institute of Veterinary Pathology, Freie Universität Berlin, Berlin, Germany; ${ }^{9}$ The Ritchie Centre, Hudson Institute of Medical Research, and h Department of Paediatrics, Monash University, Melbourne, VIC, Australia; 'Department of Medicine, University of Colorado Denver, Aurora, CO, USA; 'Department of Medicine, Radboud University Medical Center, Nijmegen, The Netherlands
\end{abstract}

\section{Keywords}

Interleukin-37 · Immunosuppression · Inflammation • Antibacterial host defense - Streptococcus pneumoniae . Pneumococcal pneumonia

\begin{abstract}
Streptococcus pneumoniae infections can lead to severe complications with excessive immune activation and tissue damage. Interleukin-37 (IL-37) has gained importance as a suppressor of innate and acquired immunity, and its effects have been therapeutic as they prevent tissue damage in autoimmune and inflammatory diseases. By using RAW macrophages, stably transfected with human IL-37, we showed a $70 \%$ decrease in the cytokine levels of IL- 6 , TNF- $\alpha$, and IL-1 $\beta$, and a 2.2-fold reduction of the intracellular killing capacity
\end{abstract}

\section{KARGER}

(C) 2017 S. Karger AG, Basel

E-Mail karger@karger.com

www.karger.com/jin of internalized pneumococci in response to pneumococcal infection. In a murine model of infection with S. pneumoniae, using mice transgenic for human IL-37b (IL-37tg), we observed an initial decrease in cytokine expression of IL-6, TNF- $\alpha$, and IL-1 $\beta$ in the lungs, followed by a late-phase enhancement of pneumococcal burden and subsequent increase of proinflammatory cytokine levels. Additionally, a marked increase in recruitment of alveolar macrophages and neutrophils was noted, while TRAIL mRNA was reduced 3-fold in lungs of IL-37tg mice, resulting in necrotizing pneumonia with augmented death of infiltrating neutrophils, enhanced bacteremic spread, and increased mortality. In conclusion, we have identified that IL-37 modulates several core components of a successful inflammatory response to pneumococcal pneumonia, which lead to increased inflammation, tissue damage, and mortality.

(c) 2017 S. Karger AG, Basel
Prof. Dr. Hortense Slevogt

Septomics Research Center, Jena University Hospital

Albert-Einstein-Strasse 10

DE-07745 Jena (Germany)

E-Mail Hortense.Slevogt@med.uni-jena.de 


\section{Introduction}

Streptococcus pneumoniae is one of the most important human respiratory pathogens and remains the most common cause of pneumonia worldwide [1]. Especially in individuals with medical comorbidity, pneumococcal disease is associated with substantial morbidity and mortality [2]. Acute pulmonary infection, caused by $S$. pneumoniae, is characterized by high bacterial burden in the lung, a pronounced alveolar influx of polymorphonuclear cells, and a risk of bacterial systemic spread [3]. It is widely assumed that excessive immune activation and tissue damage facilitate bacterial invasion, a severe complication of pneumococcal pneumonia [4]. For that reason, limiting proinflammatory cytokine responses and leukocyte influx at the suitable time is of vital importance for ensuring an appropriate resolution of inflammation. In murine pneumococcal pneumonia, it was shown that apoptotic death of alveolar macrophages (AMs), mediated by TRAIL (TNF-related apoptosis-inducing ligand), reduces lung inflammation triggered by bacterial challenge [5].

Interleukin-37 (IL-37) belongs to the family of IL-1 cytokines. Unlike other members of the family, IL-37 broadly suppresses innate immunity [6]. A growing body of evidence has found IL-37 to be a fundamental antiinflammatory cytokine, with the capacity to reduce and suppress immune responses in inflammatory and autoimmune diseases, thereby preventing tissue damage [6]. Reducing endogenous IL-37 in human cells revealed that IL-37 limits the production of cytokines induced by Tolllike receptors (TLRs) and IL- $1 \beta$ secretion [7]. Transgene expression of human IL-37 in mice (IL-37tg) results in markedly reduced inflammation in models of endotoxic shock, colitis, myocardial infarction, lung, and spinal cord injury [6, 8-11]. In addition, it was reported that intranasal administration of IL-37 prevents acute allergic inflammation in mice [12]. In parallel, in a murine infection model with Aspergillus fumigatus, treatment with recombinant exogenous IL-37 decreased pulmonary tissue damage by preventing the activation of the NLRP3 inflammasome and reducing IL- $1 \beta$ secretion [13].

Elevated levels of IL-37 have been observed in humans with chronic inflammatory and autoimmune diseases such as chronic obstructive pulmonary disease, rheumatoid arthritis, and inflammatory bowel disease, suggesting that the induction of IL-37 expression is an appropriate response to limit disease severity [14-17]. Notably, most of these chronic conditions are known to be associated with a greatly amplified risk for pneumococcal infec- tions and increased mortality $[2,18]$. In accordance, recent studies demonstrated that IL-37tg mice are more susceptible to disseminated Candida albicans infection [19]. In human tuberculosis, IL-37 has been found to inhibit the production of proinflammatory cytokines and to decrease the phagocytic activity of macrophages [20]. Hence, the anti-inflammatory and immunosuppressive properties of IL-37 might play an important role in disease progression and outcome of pneumococcal pneumonia.

In this study, we investigated the impact of IL-37 on pneumococcal infection using RAW 264.7 macrophages, stably transfected with human IL-37 and a clinically relevant IL-37 transgenic mouse model. Due to the lack of a homologous IL-37 murine gene, our studies were based on vector-controlled human IL-37 murine expression models where IL-37 expression is regulated by a constitutive CMV promoter [7]. The CMV promotor of pIRES is constitutively active, and is commonly used to drive expression in most cells. However, like other members of the IL-1 family, IL-37 shows no species specificity, and transgene expression of human IL-37 in RAW macrophages as well as in mice is similar to the expression in human cells [21]. IL-37 expression in the inflamed tissue counteracts the effective control of pneumococcal growth, greatly augments inflammation accompanied with increased influx and necrosis of neutrophils, and intensifies tissue damage.

\section{Materials and Methods}

\section{Ethics Statement}

This work was performed in accordance with the recommendations of the European Guidelines for Animal Welfare of the European Commission. All procedures were reviewed and accepted by the governmental institution Thüringer Landesamt für Verbraucherschutz (TLV) and are described in the applications for animal experiments 02-067/11 and 02-043/15.

\section{Animals}

Transgenic mice were generated using the full-length precursor CDNA of $I L-37 b$ isoform driven by the CMV promoter for constitutive expression [7]. For IL-37, 5 splice variants (IL-37a-e) were identified, at which the isoform IL-37b is the largest and includes 5 of 6 exons [22]. Referring to embryo transfer, using C57BL/6J mice, heterozygous IL-37tg siblings were mated with each other to generate homozygous IL-37tg animals. IL-37-negative siblings were bred and used as wild-type mice (WT) in all experiments. Both mice strains were kept under specific pathogenfree conditions. Mice were supplied with the same rodent chow and water and maintained on a 12-h light-dark cycle in a temperature- and humidity-controlled environment. For all experiments, we used 9-week-old female mice.
404

J Innate Immun 2017;9:403-418

DOI: $10.1159 / 000469661$
Schauer et al. 
Cells

Murine macrophages (RAW 264.7; ATCC) were stably transfected with either the IL-37b (RAW-IL-37) isoform in pIRES or pIRES-empty (RAW-vector; lacking $I L-37 b$ ), using the FuGENE HD transfection reagent (PROMEGA) [7]. The CMV promotor of pIRES is constitutively active, and is commonly used to drive expression in most cells. Stably transfected cells were cultured in Dulbecco's Modification of Eagle's Medium (DMEM; Gibco) supplemented with $10 \%$ heat inactivated fetal calf serum (FCS; Biochrom), $10,000 \mathrm{U} / \mathrm{mL}$ of penicillin, and $10,000 \mu \mathrm{g} / \mathrm{mL}$ of streptomycin) at $37^{\circ} \mathrm{C}$ in a humidified atmosphere containing $5 \% \mathrm{CO}_{2}$. Stably transfected cells were selected with Geneticin (1:100; Gibco, $50 \mathrm{mg} / \mathrm{mL}$ ), added to the medium.

\section{Bacterial Strains}

S. pneumoniae WT D39 serotype 2 (encapsulated) and the isogenic nonencapsulated D39 $\Delta c p s$ was a kind gift from Hester Bootsma, PhD (Laboratory of Pediatric Infectious Diseases, Radboud University Nijmegen Medical Center, the Netherlands). The capsular polysaccharide represents one of the most important pneumococcal virulence factors [23]. For comparison of virulence, we used for the in vitro studies the encapsulated WT D39wt serotype 2 and the nonencapsulated mutant D39 $\Delta$ cps. Based on the fact that a reduced amount of capsule can also convert the pneumococcus into a more nonpathogenic state in terms of its ability to evade the immune system [24], we only used the encapsulated D39wt for our in vivo infection studies, which reduces the amount of capsule polysaccharide for an intimate contact with host cells in vivo [24]. Both strains were grown in a first step overnight on $5 \%$ sheep blood agar plates (BD) at $37^{\circ} \mathrm{C} / 5 \% \mathrm{CO}_{2}$. Cultures were then inoculated into Todd-Hewitt Yeast (THY) medium and grown to mid-log phase (optical density at $600 \mathrm{~nm}\left[\mathrm{OD}_{600}\right]$ of 0.285 ) at $37^{\circ} \mathrm{C} / 5 \%$ $\mathrm{CO}_{2}$. Pneumococci were harvested by centrifugation at 4,500 rpm for $5 \mathrm{~min}$ and $4^{\circ} \mathrm{C}$, and resuspended in sterile PBS.

\section{Murine Infections}

IL-37tg and WT mice were anaesthetized by intraperitoneal injection of medetomidine $(0.5 \mathrm{mg} / \mathrm{kg})$, midazolam $(5 \mathrm{mg} / \mathrm{kg})$, and fentanyl $(0.05 \mathrm{mg} / \mathrm{kg})$. Mice were then infected intranasally with a single dose of $20 \mu \mathrm{L}$ of bacterial suspension (S. pneumoniae D39 $5 \times 10^{7} \mathrm{CFU}$ per mice) or an adequate volume of PBS (uninfected). We determined the optimal infection dose, leading to a $\mathrm{LD}_{90}$, by comparing $5 \times 10^{6}, 5 \times 10^{7}$, and $5 \times 10^{8} \mathrm{CFU}$ per inoculation and mouse. For every experiment, the inoculum was plated on blood agar plates and $\mathrm{CFU}$ were counted after $20 \mathrm{~h}$ of culture at $37^{\circ} \mathrm{C}$ and $5 \% \mathrm{CO}_{2}$ for control of the infection dose. Clinical conditions, rectal temperature (BAT-12 Microprobe Thermometer; Physitemp Instruments, Clifton, NJ, USA), and body weight were monitored twice a day.

\section{Bronchoalveolar Lavage Fluid and Determination of}

Bronchoalveolar Lavage Fluid Leukocyte Subsets

Leukocyte subsets in bronchoalveolar lavage fluid (BALF) were determined from whole-lung washes of uninfected and S. pneumoniae-infected mice. Animals were anesthetized by intraperitoneal injection of ketamine $(160 \mathrm{mg} / \mathrm{kg})$ and xylazine $(75 \mathrm{mg} / \mathrm{kg})$, and sacrificed by bleeding via the vena cava. Afterwards, tracheas were rinsed through a 24 -gauge needle with $800-\mu \mathrm{L}$ aliquots of cold PBS, supplemented with 10\% FCS (Biochrom) and $2 \mathrm{~mm}$ EDTA (SERVA) 3 times, followed by careful aspiration. BALF was collected in sterile tubes on ice and centrifuged at $500 \mathrm{~g}$ at $4^{\circ} \mathrm{C}$ for $10 \mathrm{~min}$. For differential cell counts, $100 \mu \mathrm{L}$ of BALF cytospin preparations were stained with Diff-Quik reagents (Medion Diagnostics). Two slides with $2 \times 100$ cells per slide were counted and the numbers of neutrophils and AMs were calculated, using the determined whole cell counts/mL BALF.

\section{Assessment of Bacterial Loads and Survival}

For the survival analysis, mice were monitored for 5 days following infection with $S$. pneumoniae or PBS (uninfected). Clinical conditions, rectal temperature (BAT-12 Microprobe Thermometer; Physitemp Instruments), and body weight were monitored every $12 \mathrm{~h}$. Mice were sacrificed when they had lost more than $20 \%$ of their initial body weight and/or exhibited a decrease in their body temperature of $\geq 4^{\circ} \mathrm{C}$. For enumeration of bacterial numbers, IL-37tg and WT mice were anesthetized at 24 or $48 \mathrm{~h}$ after infection by intraperitoneal injection of ketamine $(160 \mathrm{mg} / \mathrm{kg})$ and $\mathrm{xy}-$ lazine $(75 \mathrm{mg} / \mathrm{kg})$. Blood samples were taken and mice were finally sacrificed by bleeding via the vena cava. Subsequently, lungs and BALF were collected. Lung tissue was homogenized in $500 \mu \mathrm{L}$ of PBS without supplements using a tissue homogenizer (FastPrep-24 SPS; MP Biomedicals). CFU in lung, BALF, and blood samples were determined from serial dilutions plated on $5 \%$ sheep blood agar plates and incubated for $20 \mathrm{~h}$ at $37^{\circ} \mathrm{C} / 5 \% \mathrm{CO}_{2}$ before colonies were counted. The limit of detection was $10 \mathrm{CFU} / \mathrm{mL}$.

\section{Lung Histopathology and Immunohistochemistry}

Mice were sacrificed at 24 or $48 \mathrm{~h}$ after infection with S. pneumoniae or application of PBS. Lungs were carefully removed after ligation of the trachea as described previously [25]. The lungs were immersion-fixed in formalin and embedded in paraffin, cut in 2 - $\mu$ m-thick sections, and stained with hematoxylin and eosin after dewaxing in xylene and rehydration in decreasing ethanol concentrations. Three evenly distributed sections per lung were microscopically evaluated by a board-certified veterinary pathologist to assess dissemination and the quality of pathologic alterations using specified lung inflammation parameters as previously described [26] (total lung area affected; distribution of lung lesions; bronchitis; peribronchial, interstitial, and intra-alveolar inflammation; alveolar necrosis; perivascular inflammation and edema; infiltration by neutrophils; macrophages; pleuritic; and steatitis). The lung histopathological score is expressed as the sum of 5 parameters graded on a scale of 0 (absent) to 4 (severe): pleuritis, steatitis, pneumonia, perivascular edema, and degree of inflammation. For immunohistochemical detection of $S$. pneumoniae and active caspase-3, heat-mediated antigen retrieval was performed in $10 \mathrm{mM}$ of citric acid ( $\mathrm{pH} 6.0$ ), microwaved at $600 \mathrm{~W}$ for $12 \mathrm{~min}$. Thereafter, lung sections were incubated with a purified rabbit antibody polyclonal to $S$. pneumoniae $(1: 2,000)$ or with a purified rabbit antibody polyclonal to active caspase- $3(1: 1,000)$ at $4{ }^{\circ} \mathrm{C}$ overnight. Incubation with an immune-purified rabbit antibody at the same dilution served as a negative control. Subsequently, slides stained for $S$. pneumoniae were incubated with a secondary, alkaline phosphatase-conjugated goat anti-rabbit (1:500, AP-1000; Vector, Burlingame, CA, USA) antibody for $30 \mathrm{~min}$ at room temperature. The alkaline chromogen triamino-tritolyl-methanechloride (Neufuchsin) was used as a phosphatase substrate for color development. Slides stained for active caspase- 3 were incubated with biotinylated, secondary goat anti-rabbit IgG (1:200) antibody and HRPcoupled streptavidin. Diaminobenzidine (DAB) was used as sub- 
Table 1. Human and murine RT-qPCR primers used in this study

\begin{tabular}{llll}
\hline Human $(\mathrm{h})$ and mouse $(\mathrm{m})$ gene & Symbol & Forward primer & Reverse primer \\
\hline h-Interleukin-37 & $I L-37$ & GGAAGTCCGATTCTCCTGGGGGT & GGCCGGCGTGCTGATTCCTT \\
m-Interleukin-6 & $I L-6$ & ACCACTTCACAAGTCGGAGG & TCTGCAAGTGCATCATCGTT \\
m-Interleukin-1 beta & $I L-1 \beta$ & AGGAGAACCAAGCAACGACA & TCTGCTTGTGAGGTGCTGAT \\
m-Tumor necrosis factor alpha & TNF- $\alpha$ & GGCCTCCCTCTCATCAGTTC & TTTGCTACGACGTGGGCTAC \\
m-Ribosomal protein-L13A & $R P L 13 A$ & TACGCTGTGAAGGCATCAAC & CTCGGGAGGGGTTGGTATTC \\
m-TNF-related apoptosis-inducing ligand & TRAIL & GTGGCAGCTCACATTACTGG & TAATACAGGCCCTCCTGCTC \\
\hline
\end{tabular}

strate for color development. All slides were counterstained with hematoxylin, dehydrated through graded ethanols, cleared in xylene, and coverslipped.

\section{ELISA/Bio-Plex}

Cytokine secretion by murine RAW 264.7 cells was analyzed with the commercially available ELISA kits mouse IL-6/IL-1 $\beta$ / TNF- $\alpha$ ELISA Ready-Set-Go (eBioscience). Levels of cytokines in lung homogenates, BALF, and serum were determined by Bio-Plex Multiplex Immunoassay (Bio-Rad). Measurement of IL-37 protein in RAW 264.7 cells, lung homogenates, BALF, and serum was carried out with the IL-37 (human) ELISA kit (AdipoGen). All kits were used according to the manufacturer's protocols.

\section{RNA Isolation, cDNA Synthesis, and Reverse}

Transciption qPCR

To quantify the relative gene expression of $I L-37, I L-6, I L-1 \beta$, and TNF- $\alpha$ in vitro and in vivo, total RNA was extracted and reverse transcription $\mathrm{qPCR}$ and real-time $\mathrm{qPCR}$ were performed as previously described [27]. The expression levels were normalized to the house-keeping gene Ribosomal Protein L13A (RPL13A). The sequences of all primers used for amplification are listed in Table 1.

\section{Phagocytosis and Intracellular Killing Assay}

RAW-IL-37 and RAW-vector cells were exposed to either S. pneumoniae D39 or D39 $\Delta c p s$ with a multiplicity of infection (MOI) of 150. Phagocytosis was carried out for $60 \mathrm{~min}$ at $37^{\circ} \mathrm{C}$ and $5 \% \mathrm{CO}_{2}$. After bacterial exposure, cells were washed and incubated for $1 \mathrm{~h}$ in culture medium, containing $200 \mu \mathrm{g} / \mathrm{mL}$ of Gentamicin (Gibco), which kills extracellular bacteria but does not penetrate eukaryotic cells. Then, cells were washed twice in PBS and lysed mechanically with a tissue homogenizer (FastPrep-24 SPS; MP Biomedicals). The number of ingested bacteria was determined by quantitative plating of serial dilutions of the lysates on sheep blood agar plates and incubation at $37^{\circ} \mathrm{C}$ and $5 \% \mathrm{CO}_{2}$ for $20 \mathrm{~h}$. The limit of detection was $10 \mathrm{CFU} /$ well. Gentamicin activity was verified by plating supernatants after $1 \mathrm{~h}$ of incubation with Gentamicin. To demonstrate phagocytized bacteria by RAW cells, D39wt and $\mathrm{D} 39 \Delta c p s$ were grown to mid-log phase $\left(\mathrm{OD}_{600}\right.$ of 0.285$)$ at $37^{\circ} \mathrm{C} / 5 \%$ $\mathrm{CO}_{2}$ and labeled with fluorescein isothiocyanate (FITC; $0.2 \mathrm{mg}$ per $10^{8}$ bacteria) for $1 \mathrm{~h}$ at room temperature and $150 \mathrm{rpmi}$. Bacteria were then washed 4 times with PBS and added to the cells. Phagocytosis assay was carried out as described before. After quenching of the FITC signal of extracellular adherent bacteria with ethidium bromide ( $1 \mathrm{mg} / \mathrm{mL}$ cell suspension; Sigma-Aldrich), confocal DIC-fluorescence microscope images of the cells with ingested,
D39wt, and D39 $\Delta c p s$ were taken (ZEISS Axio Vert.1). To monitor intracellular killing capacity, cells could phagocytize D39 $\Delta c p s$ for $60 \mathrm{~min}$. Then, cells were washed and Gentamicin $(200 \mu \mathrm{g} / \mathrm{mL})$ was added for $1 \mathrm{~h}$. 120, 180, and 240 min after stimulation, cells were washed, lysed, and plated as described for the phagocytosis assay. The killing efficiency of the internalized bacteria was calculated using the following equation: intracellular killing $=\{[\mathrm{CFU}(60 \mathrm{~min})$ - CFU(240 min)]/CFU(60min) $\} \times 100 \%$. For studies with recombinant IL-37, cells were preincubated with $100 \mu \mathrm{g} / \mathrm{mL}$ recombinant IL-37 for $4 \mathrm{~h}$ and then had the same procedure for the killing assay as described before. According to the manufacturers, who measured its activity by its binding ability in a functional ELISA, we used recombinant human IL-37/IL-1F7 protein (R\&D).

\section{Statistics}

GraphPad Prism5 software was used to perform statistical analysis and provide graphical presentation. One-way analysis of variance (ANOVA) followed by Dunnett's Multiple Comparison Test (Dunn test) was performed to analyze IL-37mRNA and IL-37 protein levels. Significant differences between treatment groups (WT vs. IL-37tg mice; RAW-vector vs. RAW-IL-37) were analyzed with the Student $t$ test. Survival curves were compared by log-rank test. In all cases, $p<0.05$ was considered statistically significant.

\section{Results}

IL-37 Is Upregulated by S. pneumoniae and Reduces Cytokine Expression in Murine RAW Macrophages

AMs play a pivotal role in the orchestration of innate immune responses by controlling pneumococcal growth in the lower airways [5]. Thereby, AMs and lung epithelial cells release proinflammatory cytokines and chemokines to activate a neutrophilic response. The exaggerated neutrophil response worsens the clinical features of pneumonia and is associated with severe lung injury [28]. IL37 is upregulated during inflammation and downregulates the inflammatory response of macrophages [6]. We therefore investigated the expression profile and the immunomodulatory properties of human IL-37 in murine macrophages (RAW 264.7) after stimulation with pneumococci. RAW macrophages, stably transfected with ei-
406

J Innate Immun 2017;9:403-418 DOI: $10.1159 / 000469661$
Schauer et al. 


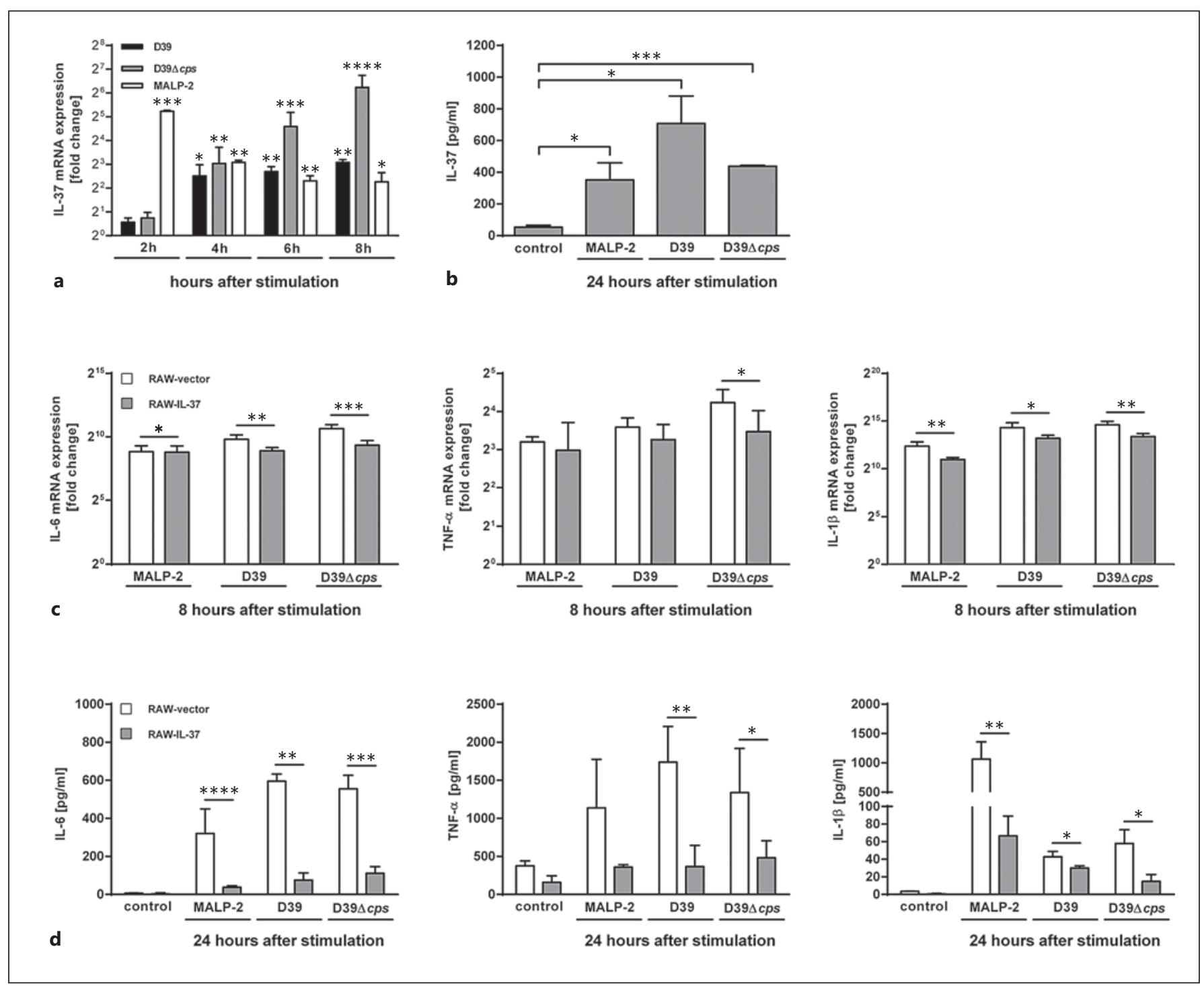

Fig. 1. IL-37 is upregulated by S. pneumoniae and reduces cytokine expression in murine RAW macrophages. RAW 264.7 cells, stably transfected with either pIRES-IL-37b (RAW-IL-37) or pIRESempty (RAW-vector), were stimulated with D39, D39 $\Delta$ cps (MOI $0.05)$, or MALP-2 $(0.1 \mu \mathrm{g} / \mathrm{mL})$ and incubated as indicated. a IL-37 mRNA expression level in RAW-IL-37 cells normalized to untreated controls analyzed by qPCR after the indicated period of stimulation. $\mathbf{b}$ Measurement of IL-37 protein from cell culture supernatants of RAW-IL-37 cells at the indicated time point by ELISA. c Cytokine mRNA of IL-6, IL-1 $\beta$, and TNF- $\alpha$ of RAW-vector

ther pIRES-IL-37b (RAW-IL-37) or pIRES-empty (RAWvector; lacking human $I L-37 b)$, were stimulated with the encapsulated S. pneumoniae strain D39, with the isogenic nonencapsulated deletion mutant strain D39 $\Delta c p s$, or with the TLR2/6 agonist macrophage-activating lipopeptide-2 (MALP-2) (Fig. 1a, b).

Streptococcus pneumoniae Infection in an IL-37tg Mouse Model and RAW-IL-37 cells at the indicated time point by qPCR. Values are normalized to uninfected controls. d Detection of cytokine protein levels of IL- 6 , IL- $1 \beta$, and TNF- $\alpha$ in cell culture supernatants of RAW-vector and RAW-IL-37 cells at the indicated time point by ELISA. Column bars of $\mathbf{b}$ and $\mathbf{d}$ show means with standard deviations. Values of $\mathbf{a}$ and $\mathbf{c}$ are represented as means with standard errors. Shown are representative data of 3 independent experiments (a-d). ${ }^{*} p<0.05$; ${ }^{* *} p<0.005$; ** $p<0.0005$; $* * * * p<0.0001$.

Each of the 3 stimuli (D39, D39 $\Delta c p s$, MALP-2) induced a significant increase of IL-37 mRNA. Treatment of RAW-IL-37 cells with MALP-2 induced a 16-fold increase in IL-37 mRNA already detectable after $2 \mathrm{~h}$ of stimulation. Thereafter, levels of IL-37 mRNA decreased to a 4 -fold expression at $8 \mathrm{~h}$. Exposure to S. pneumoniae led

J Innate Immun 2017;9:403-418 DOI: $10.1159 / 000469661$ 


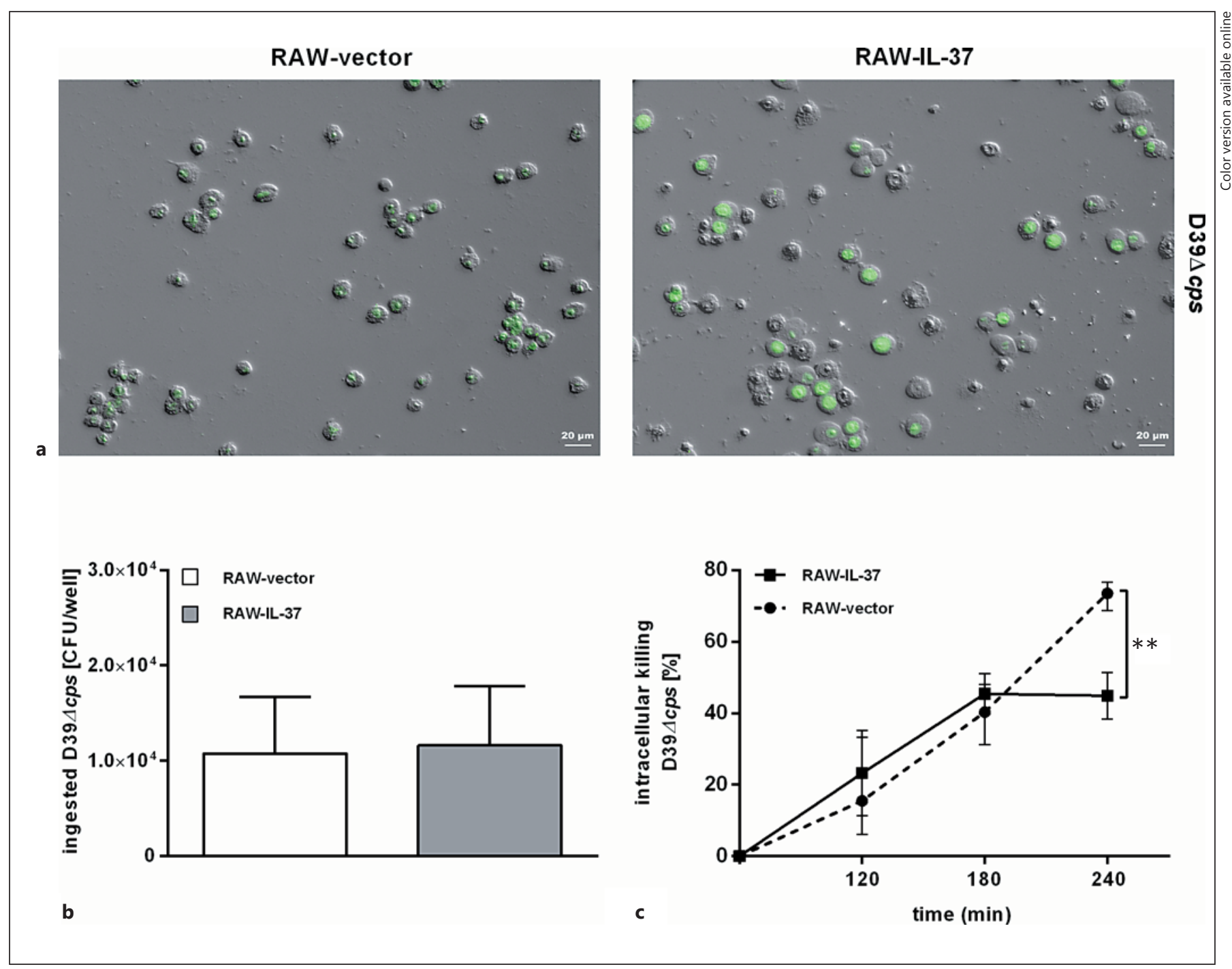

Fig. 2. IL-37 expression increases intracellular survival of S. pneumoniae in murine RAW macrophages. RAW 264.7 cells, stably transfected with either pIRES-IL-37b (RAW-IL-37) or pIRESempty (RAW-vector), were stimulated with D39 $\Delta c p s$ (MOI of 150). a Overview of DIC/FITC microscope images of RAW macrophages with ingested, fluorescent FITC-labeled D39 $\Delta$ cps $60 \mathrm{~min}$ after infection. Twenty-fold magnification. FITC signal of extracellular bacteria was quenched with ethidium bromide. Phagocytosis (b) and intracellular (c) survival of ingested D39 $\Delta c p s$. Cells

to a significant 4 -fold increase in IL-37 mRNA after $4 \mathrm{~h}$ and then further increased to 32 -fold in response to D $39 \Delta c p s$ challenge at $8 \mathrm{~h}$ (Fig. 1a). However, unless there was stimulation, only minor mRNA of IL-37 were detected (data not shown). In addition, all 3 stimulations led to a significant IL-37 protein secretion, detectable by ELISA of cell culture supernatants after $24 \mathrm{~h}$ of stimulation (Fig. 1b). could phagocytose bacteria for $60 \mathrm{~min}$. Subsequently, Gentamicin $(200 \mu \mathrm{g} / \mathrm{mL})$ was added for $1 \mathrm{~h}$ and the number of intracellular bacteria was determined by quantitative plating of the cell lysates. Data in a are shown as CFU of recovered bacteria per well. Data in b are expressed as the percentage of surviving bacteria per well 120, 180 , and $240 \mathrm{~min}$ after stimulation relative to the number of recovered bacteria after $60 \mathrm{~min}$ of stimulation (=100\%). Two wells/ group obtained from 3 independent experiments. Mean values with standard errors are shown.

Next, we analyzed the impact of IL-37 expression and secretion on the production of proinflammatory cytokine mRNAs and protein levels of IL- 6 , TNF- $\alpha$, and IL- $1 \beta$ after stimulation with $S$. pneumoniae (Fig. 1c, d). In RAWIL-37 cells, stimulation with D39, D39 $\Delta c p s$, and MALP-2 significantly reduced mRNA and protein levels of IL-6, TNF- $\alpha$, and IL- $1 \beta$ compared to RAW vector cells. 


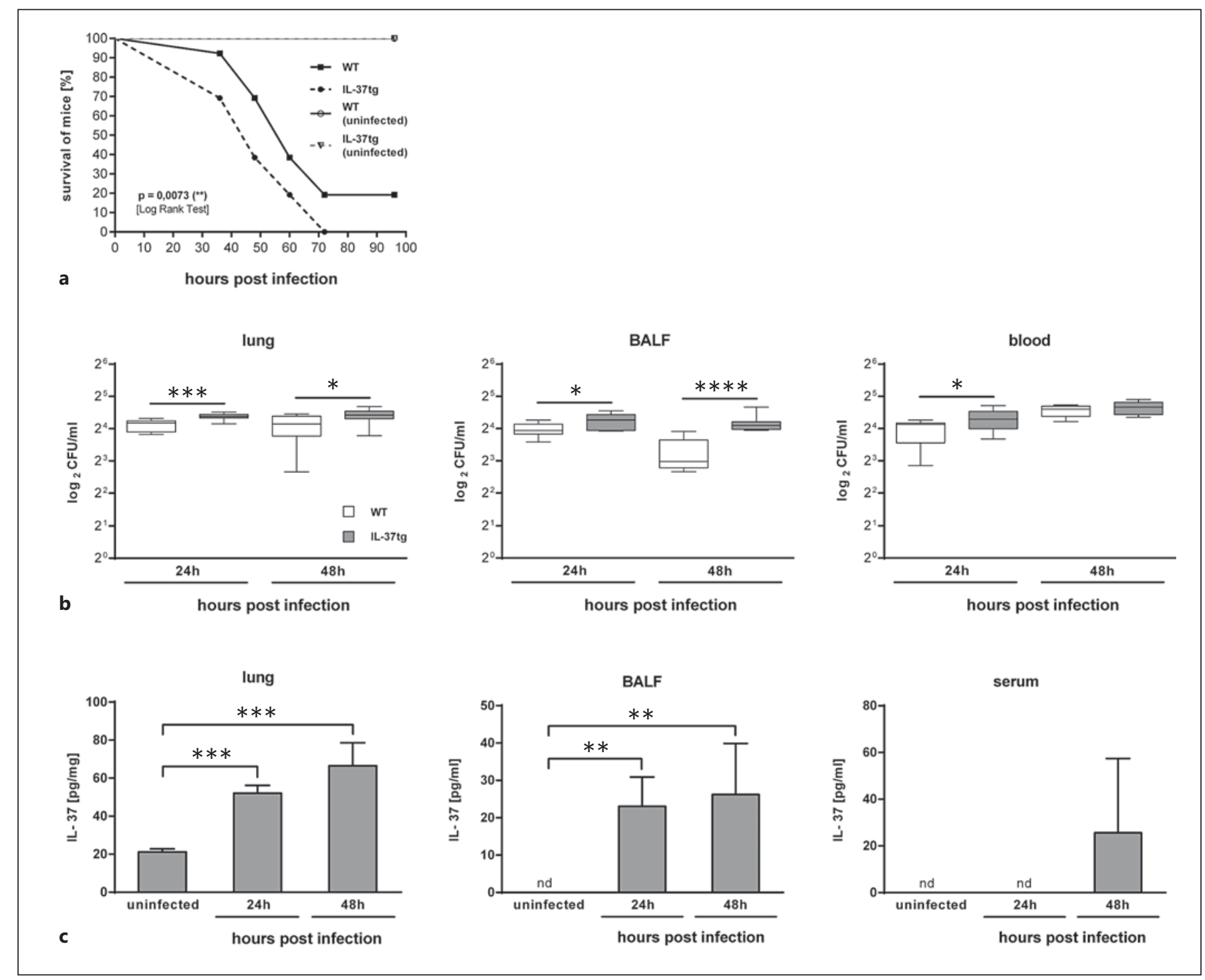

Fig. 3. IL-37tg mice exhibit enhanced bacterial spread and increased mortality upon challenge with $S$. pneumoniae. WT and IL-37tg mice were inoculated intranasally with S. pneumoniae D39 $\left(5 \times 10^{7} \mathrm{CFU} /\right.$ mouse) or treated with PBS (uninfected). a KaplanMeier survival plot. Survival rate was assessed over the 96 -h period following infection. b Bacterial loads of S. pneumoniae in lung homogenates, BALF, and blood at 24 and $48 \mathrm{~h}$ after infection. Limit of detection was $10 \mathrm{CFU} / \mathrm{mL}$. c Detection of IL-37 protein in lung homogenates, BALF, and serum of IL-37tg mice relative to unin-

\section{RAW-IL-37 Macrophages Possess Impaired}

Intracellular Killing of S. pneumoniae

To investigate whether IL-37 expression has an impact on macrophage phagocytic activity during pneumococcal stimulation, RAW-IL-37 and RAW-vector cells were exposed to either $S$. pneumoniae $\mathrm{D} 39$ or D39 $\Delta$ cps $(\mathrm{MOI}=$ fected controls by ELISA. Detection limit: $15 \mathrm{pg} / \mathrm{mL}$. Data in $\mathbf{b}$ are given as box and whisker plots showing the smallest observation, the lower quartile, the median, the upper quartile, and the largest observation. Bars in c show mean expressions with standard deviations. $n=26$ mice (a); $n=10$ mice (b); $n=4$ mice (c) per group and time point of $\mathrm{n} \geq 2$ independently performed experiments. ${ }^{*} p<0.05$; $^{* *} p<0.005$; $^{* * *} p<0.0005$; ${ }^{* * * *} p<0.0001$ vs. uninfected controls (c) or WT vs. IL-37tg mice (a, b).

150). While phagocytosed D39 were rarely seen, or absent in both cell lines (online suppl. Fig. S1; for all online suppl. material, see www.karger.com/doi/10.1159/000469661), the nonencapsulated mutant $\mathrm{D} 39 \Delta c p s$ was phagocytosed by the cells (Fig. 2a). Both, RAW-vector and RAW-IL-37 cells showed similar numbers of ingested D39 $\Delta c p s$ pneu-

J Innate Immun 2017;9:403-418 DOI: $10.1159 / 000469661$ 


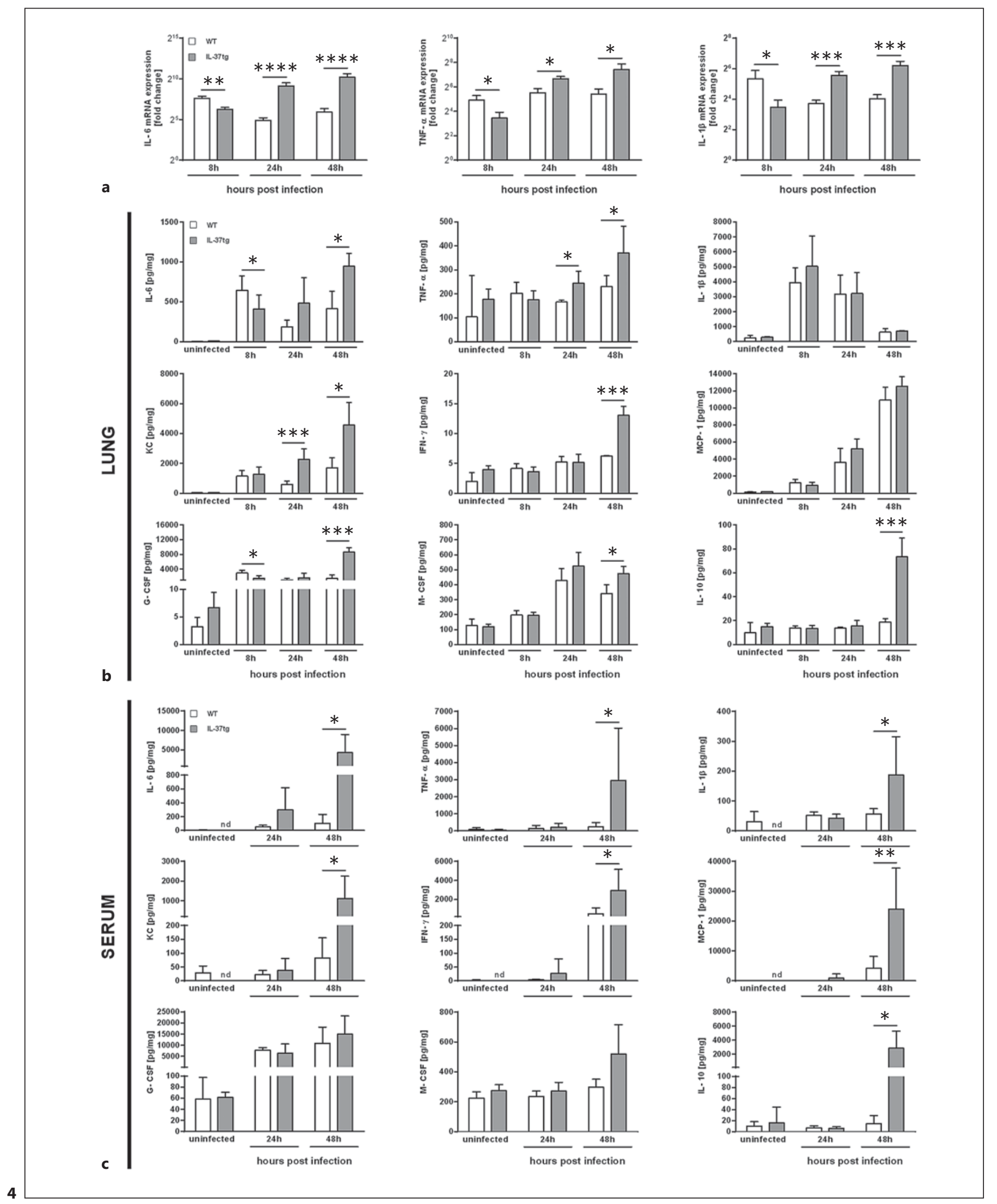

(For legend see next page.) 
mococci with no differences related to the phagocytosis potential (Fig. 2b).

Next, we analyzed the intracellular killing capacity of phagocytosed pneumococci by RAW macrophages. IL37-expressing RAW cells demonstrated a 2.2-fold increase of viable bacteria recovered from the cells compared to RAW-vector cells (Fig. 2c). Two hundred and forty minutes after stimulation with S. pneumoniae, only $25 \%$ of the ingested bacteria from RAW-vector cells were still alive, whereas in RAW-IL-37 cells the survival of intracellular pneumococci was 55\% (Fig. 2c). In contrast, we observed no difference in case of the killing capacities when we compared RAW-vector cells, which were preincubated with recombinant IL-37, with RAW-vector cells without recombinant IL-37 (online suppl. Fig. S2). Given the fact that IL-37 protein accumulates within macrophages over a time period of $24 \mathrm{~h}$, at which time IL-37 protein is not detectable in the supernatant but is detectable in the nucleus and the cytosol after stimulation of RAW-IL-37 cells with $S$. pneumoniae (online suppl. Fig. S3), these data indicate that intracellular but not secreted IL-37 decreased the ability of RAW macrophages to kill intracellular pneumococci.

\section{IL-37tg Mice Exhibit Enhanced Bacterial Spread and}

Increased Mortality upon Challenge with

\section{S. pneumoniae}

To investigate the impact of IL-37 in vivo in a pneumococcal pneumonia infection model, WT and IL-37tg mice were infected intranasally with D39 or treated with the same volume of PBS (uninfected) as control. Infected IL-37tg mice showed a significantly increased mortality compared to WT mice (Fig. 3a). Seventy-two hours after infection, $20 \%$ of WT mice were still alive, with no further mice dying over the next $24 \mathrm{~h}$, while the IL-37tg mice exhibited $100 \%$ mortality $72 \mathrm{~h}$ after infection (Fig. 3a).

In accordance with the increased mortality, $24 \mathrm{~h}$ after infection, IL-37tg mice showed significantly higher bacterial counts in lung homogenates, BALF, and peripheral blood compared to WT mice (Fig. 3b). Forty-eight hours after infection, bacterial loads in IL-37tg mice were still

Fig. 4. Transgene expression of IL-37 in the lung exerts biphasic effects on cytokine production after pneumococcal infection. WT and IL-37tg mice were challenged intranasally with S. pneumoniae D39 $\left(5 \times 10^{7} \mathrm{CFU} /\right.$ mouse) or treated with PBS (uninfected). Lungs and peripheral blood were collected at the indicated time points for analysis of: mRNA expression of IL- 6, IL- $1 \beta$ and TNF- $\alpha$ in lung homogenates normalized to uninfected controls by qPCR (a), and

Streptococcus pneumoniae Infection in an

IL-37tg Mouse Model significantly higher in lung homogenates and BALF compared to WT mice, while in the peripheral blood, bacterial counts reached similar numbers in both groups (Fig. 3b).

Despite a constitutively active cytomegaly (CMV) promotor, transgene expression of IL-37 is low unless there is stimulation in mouse and human cell lines as well as in IL-37tg mice models [7, 29-31]. To determine whether infection with $S$. pneumoniae induces the expression of the IL-37 transgene, we assessed the in vivo kinetics of IL37 by analyzing IL-37 mRNA in lung homogenates (online suppl. Fig. S4) as well as protein levels in the lung, BALF, and serum of infected IL-37tg mice (Fig. 3c). Although baseline expression was minimal (data not shown), IL-37 mRNA levels were increased at $8 \mathrm{~h}$ after infection, followed by a secondary increase at $24 \mathrm{~h}$ after infection (online suppl. Fig. S4). Thereafter, $48 \mathrm{~h}$ after infection, the levels decreased. In addition, we observed in IL-37tg mice that IL-37 protein levels in lung homogenates and BALF increased significantly relative to uninfected controls 24 and $48 \mathrm{~h}$ after infection (Fig. 3c). In contrast, we found only marginal amounts IL-37 protein in the serum of infected IL-37tg mice, detectable only $48 \mathrm{~h}$ after infection (Fig. 3c). These data indicate that pulmonary S. pneumoniae infection, which resulted in an enhanced early spread of the pathogen and increased mortality, was required for the induction of IL-37.

\section{Transgene Expression of IL-37 in the Lung Exerts}

Biphasic Effects on Cytokine Production after

Pneumococcal Infection

Based on the increased systemic spread of $S$. pneumoniae in infected IL-37tg mice, we hypothesized that IL-37tg mice would exhibit hyperinflammatory responses after pneumococcal infection. Therefore, we analyzed the mRNA levels of the proinflammatory cytokines IL-6, IL- $1 \beta$, and TNF- $\alpha$ in the lungs of infected animals at 8,24 , and $48 \mathrm{~h}$ after infection (Fig. $4 \mathrm{a}$ ). At $8 \mathrm{~h}$ after infection, we observed significantly lower mRNA levels of IL-6, IL-1 $\beta$, and TNF- $\alpha$ in the lungs of IL-37tg mice compared to lungs of WT mice (Fig. 4a). This initial lower expression was followed by a significant increase and higher expres-

cytokine protein levels of IL-6, TNF- $\alpha$, IL- $1 \beta, \mathrm{KC}$, IFN- $\gamma$, MCP-1, G-CSF, M-CSF, and IL-10 in lung homogenates and serum by BioPlex $(\mathbf{b}, \mathbf{c})$. Values of $\mathbf{a}$ are represented as means \pm SEM. Column bars of $\mathbf{b}$ and $\mathbf{c}$ show means with standard errors. $n \geq 6$ mice (a), $n=4$ mice (b) per group and time point of $n \geq 2$ independently performed experiments. ${ }^{*} p<0.05$; ${ }^{* *} p<0.005$; ${ }^{* * *} p<0.0005$; **** $p<0.0001 \mathrm{WT}$ vs. IL-37tg mice.

J Innate Immun 2017;9:403-418

DOI: $10.1159 / 000469661$ 


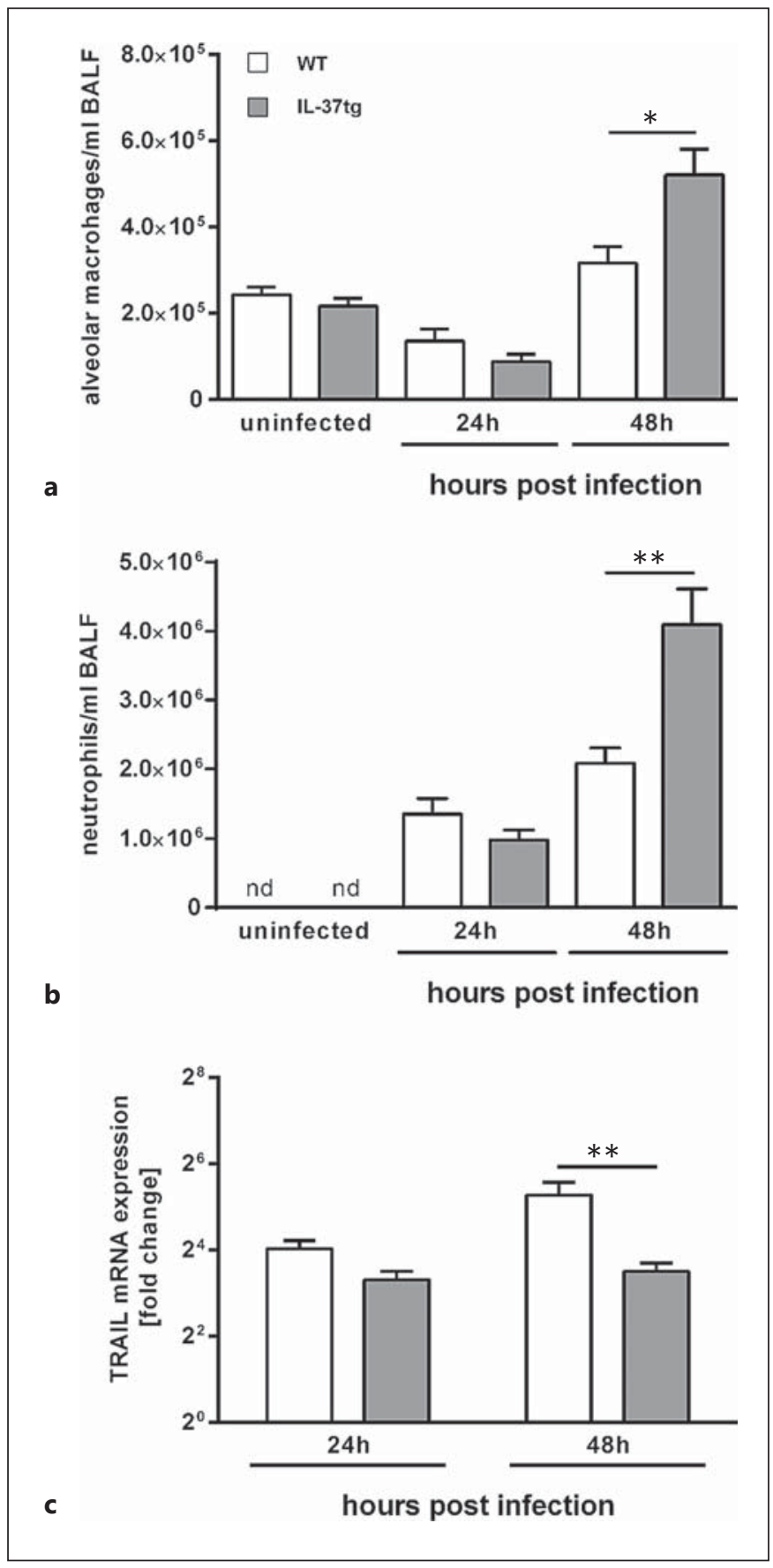

Fig. 5. Infected IL-37tg mice show increased alveolar macrophage and neutrophil recruitment and decreased pulmonary TRAIL expression. WT and IL-37tg mice were inoculated intranasally with S. pneumoniae D39 $\left(5 \times 10^{7} \mathrm{CFU} /\right.$ mouse) or treated with PBS (uninfected). a Alveolar macrophage numbers in BALF 24 and $48 \mathrm{~h}$ after infection. b Neutrophil numbers in BALF 24 and $48 \mathrm{~h}$ after infection. c Analysis of mRNA expression of TRAIL in lung homogenates 24 and $48 \mathrm{~h}$ after infection normalized to uninfected controls by qPCR. Column bars are represented as means with standard errors. $n \geq 4$ (a) b); $n \geq 5$ (c) mice per group and time point of $n \geq 2$ independently performed experiments. ${ }^{*} p<0.05$; ${ }^{* *} p<0.005$ WT vs. IL-37tg mice. sion of IL- 6 , IL- $1 \beta$, and TNF- $\alpha$ mRNA in the lungs of IL$37 \mathrm{tg}$ mice compared to WT mice, beginning at $24 \mathrm{~h}$ after infection (Fig. 4a). In addition, we measured a panel of cytokines and chemokines during pneumococcal infection at the indicated time points (Fig. 4b, c; online suppl. Fig. S5). In accordance with the mRNA levels, we could observe significant lower levels of IL-6 and G-CSF protein $8 \mathrm{~h}$ after infection in the lungs of IL-37tg mice compared to WT mice, while the other measured cytokines showed similar protein contents in the lungs of both groups. During the course of infection, most cytokines were markedly higher in IL-37tg mice, particularly $48 \mathrm{~h}$ after infection, including IL-6, TNF- $\alpha, \mathrm{KC}, \mathrm{IFN}-\gamma$, GCSF, M-CSF, and IL-10 in the lungs (Fig. 4b); IL-6, TNF- $\alpha$, IL- $1 \beta, \mathrm{KC}$, IFN- $\gamma$, MCP-1 (CCL2), and IL- 10 in the serum (Fig. 4c); and MCP-1 (CCL2), G-CSF and IL-10 in BALF (online suppl. Fig. S5). These data indicate that IL-37 critically modulates the inflammatory responses during the early phase of pneumococcal pneumonia by reducing the amounts of proinflammatory cytokines. This early phase with reduced proinflammatory cytokine expression is followed by a second phase of exaggerated cytokine and chemokine release as a response to the systemic spread of $S$. pneumoniae in IL-37tg mice compared to WT animals.

\section{Infected IL-37tg Mice Show Increased Alveolar}

Macrophage and Neutrophil Recruitment and

Decreased Pulmonary TRAIL Expression

KC and CCL2 play a key role in regulating leukocyte migration into inflamed murine lung tissue $[32,33]$. To investigate whether the observed differences in mortality between WT and IL-37tg mice are associated with differences in leukocyte recruitment into the infected lungs, we examined alveolar leukocyte numbers in WT and IL-37tg mice infected with $S$. pneumoniae via Diff-Quik staining (Fig. 5a, b; online suppl. Fig. S6). Notably, $48 \mathrm{~h}$ after infection we observed 2-fold higher counts of AMs in the BALF of IL-37tg mice relative to WT mice (Fig. 5a). We also observed a doubling of the number of neutrophils in the BALF of IL-37tg mice relative to WT mice $48 \mathrm{~h}$ after infection (Fig. 5b). Neutrophils have been identified to be the primary source of TRAIL expression in the lungs of S. pneumoniae-infected mice. Increased levels of TRAIL have been shown to induce AM apoptosis, which reduces inflammation during pneumococcal pneumonia [5]. To investigate whether IL-37 expression modulates the expression of TRAIL, we examined TRAIL mRNA levels in the lungs of IL-37tg mice and in WT mice (Fig. 5c). Fortyeight hours after infection, we observed a significant 3 -fold reduction of TRAIL mRNA expression in the lungs 
of IL-37tg mice compared to WT mice (Fig. 5c). Overall, these data support the important role of the S. pneumoniae-induced IL-37 expression for impeding pathogen clearance and deteriorating immunopathology.

\section{Transgene IL-37 Expression Results in Augmented} Death of Neutrophils, Increased Tissue Damage, and Pneumococcal Overgrowth after Pneumococcal Infection

Excessive infiltration of neutrophils in the lungs has been demonstrated to result in augmented tissue destruction $[34,35]$. To elucidate the effect of the IL-37-mediated massive influx of neutrophils into alveolar spaces and reduced TRAIL expression levels on pulmonary tissue damage, lungs of S. pneumoniae-infected IL-37tg and WT mice were dissected $48 \mathrm{~h}$ after infection and $2-\mu \mathrm{m}$ sections were prepared and stained with hematoxylin and eosin or with an anti-active caspase- 3 antibody or anti-S. pneumoniae antibody for histopathological and immunohistochemical analyses (Fig. 6a-d). Pneumococcal infection resulted in severe suppurative pleuropneumonia in both groups. WT mice had prominent infiltration of numerous intact neutrophils into the lung parenchyma and perivascular areas, consistent with predominantly suppurative pneumonia, without much necrosis of the lung parenchyma (Fig. 6a, b, left panels). In contrast, IL-37tg mice had excessive multifocal to confluent parenchymal necrosis, accompanied by massive neutrophil cell death, as indicated by neutrophil fragmentation, decay, loss of cellular details, accumulation of cellular and karrhyorectic debris, and karyorhexis, karyopyknosis, and karyolysis (Fig. 6a, b, right panels). Furthermore, active caspase- 3 immunostaining as a marker for apoptotic cell death labeled only a few randomly scattered cells in the inflamed lung parenchyma without differences between the WT and IL-37tg mice (online suppl. Fig. S7, arrowheads). Specifically, areas of tissue necrosis in the IL-37tg mice were devoid of active caspase- $3 \mathrm{immu}-$ nolabeling (online suppl. Fig. S7, asterisks), ruling out the involvement of apoptosis. Importantly, in IL-37tg mice, a large number of pneumococci were present predominantly in perivascular spaces, which were far fewer in number in WT mice (Fig. 6c, arrowhead, stained in red). Using a lung histopathology score assessing the percentage of affected lung area, significantly more widespread lung inflammation was observed in the IL-37tg mice relative to WT mice $48 \mathrm{~h}$ after infection (Fig. $6 \mathrm{~d}$ ). These data suggest that the increased mortality of IL-37tg mice was due to impaired bacterial killing with overgrowth and spread of pneumococci, massive necrosis of lung parenchyma, and marked death of neutrophils.

Streptococcus pneumoniae Infection in an IL-37tg Mouse Model

\section{Discussion}

In this study, we investigated the functional role of IL37 in host defense against $S$. pneumoniae. Here, we show that IL-37, expressed in lung tissue during infection, increases bacterial spread and disease pathology of pneumococcal pneumonia. Our in vitro results are in agreement with recent findings describing IL-37 as an inhibitor of the innate immune system by suppressing important proinflammatory cytokines after TLR stimulation of murine macrophages [7]. We observed that the stimulation of RAW macrophages with $S$. pneumoniae reduced the production of the proinflammatory cytokines IL-6, TNF- $\alpha$, and IL- $1 \beta$ in RAW-IL-37 cells compared to RAW-vector cells. Importantly, expression of IL-37 led to an enhanced intracellular survival of S. pneumoniae. We further showed in a murine infection model that mice, expressing IL-37, exhibited significantly increased mortality compared to WT mice upon infection with S. pneumoniae. During the early phase of infection, IL-37tg mice revealed limited proinflammatory cytokine responses during pneumococcal infection which was followed by an excessive increase in bacterial burden and increased expression of cytokines and chemokines in the lungs at later time points of infection. In parallel, we observed an enhanced alveolar recruitment of AMs and neutrophils, while TRAIL expression was significantly decreased in the lungs of the infected IL-37tg mice. This resulted in both increased neutrophil influx and massive colonization of pneumococci in the lungs leading to prominent necrotizing lung tissue damage and increased mortality.

As a fundamental suppressor of innate immune functions, IL-37 has been shown to be expressed by human blood monocytes, tissue macrophages, and other immune cells in response to the TLR2 and TLR4 agonists MALP-2 and LPS [6]. Due to the lack of a homologous IL-37 murine gene, our studies were based on vector-controlled human IL-37 murine expression models where IL37 expression is regulated by a constitutive CMV promoter [7]. However, like other members of the IL-1 family, IL-37 shows no species specificity, and transgene expression of human IL-37 in RAW macrophages as well as in mice is similar to the expression in human cells [21]. In our study, we show that unless there is stimulation, only minor IL-37 levels were detected in RAW-37 macrophages as well as in IL-37tg mice. However, upon exposure with S. pneumoniae, IL-37 expression and secretion progressively increased in vitro and in vivo. The abundance of IL-37 transcripts is low under steady-state conditions in dendritic cells and human blood monocytes.

J Innate Immun 2017;9:403-418

DOI: $10.1159 / 000469661$ 


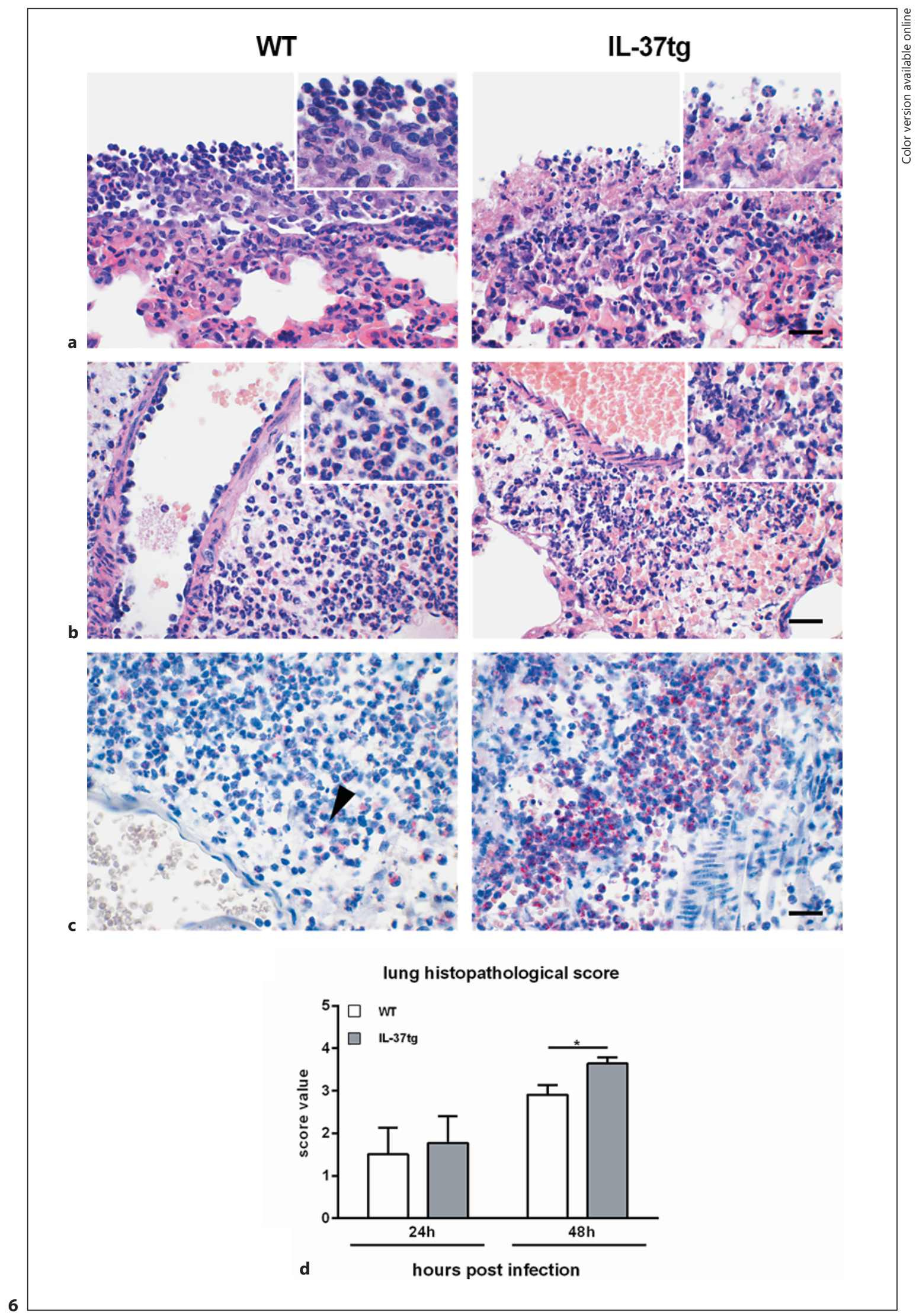

(For legend see next page.) 
This is due to an instability sequence in the IL-37b-coding region which induces constitutive downregulation of IL$37 \mathrm{~b}$ mRNA in transfected cells unless stimulated, and indicates that mRNA stabilization is the relevant mechanism to regulate IL-37 expression in IL-37-transfected murine as well as in human macrophages [31]. In addition, constitutive expression of human IL-37 was low in in vivo models of spinal cord injury and DSS-induced colitis $[29,30]$. In parallel, our data suggest that inflammatory conditions, caused by $S$. pneumoniae, increase the half-life of IL-37 mRNA and allows for translation of the IL-37 protein. The observed discrepancy between the mRNA expression levels and the corresponding protein contents of IL- 6 , TNF- $\alpha$, and IL- $1 \beta$ could be explained by the fact that mRNAs are produced at a much lower rate than proteins in mammalian cells. While a mammalian cell produces 2 copies of a given mRNA per hour, dozens of copies of the corresponding protein per mRNA per hour is produced. Similarly, mRNAs are less stable than proteins, with an average half-life of 2.6-7 versus $46 \mathrm{~h}$, respectively $[36,37]$. The long half-lives of proteins have been confirmed by independent studies in other systems $[38,39]$. Therefore, the mRNA level of a gene does not usually predict its protein level.

The elimination of bacteria from the lungs and the prevention of systemic dissemination is the key objective in host defense in pneumococcal pneumonia. This is initiated by detection and phagocytosis of $S$. pneumoniae by innate immune cells and the secretion of cytokines and chemokines to coordinate the second-line immune defense [40]. Thereby, AMs are important early effectors of innate immune responses against $S$. pneumoniae. These specialized cells are efficient in the killing of internalized pneumococci. However, this process is known to become overwhelmed when bacterial numbers increase [41]. Importantly, we observed that IL-37 expression in RAW macrophages decreased the capacity of these cells to kill pneumococci intracellularly. In contrast, we saw no difference in the killing capacity when we added recombinant IL-37 to RAW-vector cells and compared it to RAW-

Fig. 6. Transgene IL-37 expression results in augmented death of neutrophils, increased tissue damage, and pneumococcal overgrowth after pneumococcal infection. WT and IL-37tg mice were inoculated intranasally with $S$. pneumoniae D39 $\left(5 \times 10^{7} \mathrm{CFU} /\right.$ mouse). a-c Lung histology $48 \mathrm{~h}$ after infection. 2- $\mu \mathrm{m}$ lung sections were stained with hematoxylin and eosin $(\mathbf{a}, \mathbf{b})$ or with an anti-S. pneumoniae antibody (c) for histopathological and immunohistochemical analysis. Representative images are shown.

Streptococcus pneumoniae Infection in an

IL-37tg Mouse Model vector cells without preincubation with recombinant IL37. Previous studies showed that IL-37 is present in the cytoplasm and in the nucleus, and thus acts intracellularly after LPS stimulation of stably transfected RAW macrophages [21]. We also could detect IL-37 protein in the nucleus and the cytoplasm, but not in the supernatant within $24 \mathrm{~h}$ of stimulation with S. pneumoniae. This suggests that the observed impaired killing capacity of pneumococci by RAW macrophages is likely not an effect of secreted but of intracellular IL-37.

In parallel, our findings of increased pneumococcal burden in IL-37tg mice at later stages of the disease suggest that the IL-37-mediated decrease in the killing capacity of pneumococci by RAW macrophages might be related to an early failure of this first-line pulmonary defense for the clearance of pneumococci. Moreover, our data suggest that the increase in pneumococcal burden in IL-37tg mice may activate AMs in a larger area of the infected lung, resulting in subsequent elevated cytokine and chemokine production [42]. This is demonstrated by the fact that after the initial phase, when IL-37 expression reduces the proinflammatory response in the infected lungs on the mRNA and protein level, an increased expression of cytokines and chemokines was detected at later time points. Therefore, the initially reduced secretion of cytokines and chemokines and the reduction of intracellular killing capacity of macrophages, mediated by IL-37, results in increased numbers of infiltrating neutrophils at a later time point, enabling increased survival and spreading of S. pneumoniae in the infected lungs of IL-37tg mice. Uncontrolled spreading of the bacteria leads to a larger area of inflamed lung tissue that result in a secondary phase of the disease, characterized by a massive release of cytokines and chemokines in the inflamed lung tissue. This is followed by increasing numbers of infiltrating leukocytes and massive tissue damage, evoked by activated macrophages due to lower expression levels of TRAIL in the infected lungs of IL-37tg mice.

Pneumococcal pneumonia is characterized by an intense inflammatory response, orchestrated mainly by cy-

d Lung histopathological score, expressed as the sum of 5 parameters graded on a scale of 0 (absent) to 4 (severe): pleuritis, steatitis, pneumonia, perivascular edema, and degree of inflammation. Data were assessed 24 or $48 \mathrm{~h}$ after infection. Values of $\mathbf{d}$ are represented as means with standard deviations. $n=6(\mathbf{a}-\mathbf{d})$ mice per group of $\mathrm{n} \geq 2$ independently performed experiments. ${ }^{*} p<0.05$; ${ }_{* *} p<0.005 \mathrm{WT}$ vs. IL-37tg mice. Bar $(\mathbf{a}-\mathbf{c})=20 \mu \mathrm{m}$.
J Innate Immun 2017;9:403-418

DOI: $10.1159 / 000469661$ 
tokines. Thereby, the infection is a dynamic process where time has taken an important role referring to bacterial growth $[43,44]$. Our data suggest that the early suppression of proinflammatory cytokines by IL-37 in the initial phase during infection with $S$. pneumoniae is crucial in determining whether the infection might be controlled or progresses to bacteremic disease. Therefore, each cytokine, upregulated in response to the IL-37-induced modulation of the immune response, might be specifically involved in exacerbating disease pathology. The downregulation of IL-1 $\beta$, which has been shown to be required for protective immunity against respiratory infections with $S$. pneumoniae, may aggravate the pathogen ability to invade sterile compartments where it can continue multiplication without being eliminated $[45,46]$. Moreover, the elevated levels of IL-1 $\beta$, which we observed later in infected IL-37tg mice, have the potential to aggravate tissue damage [13]. In the early phase of infection, we also detected decreased TNF- $\alpha$ levels in the IL-37tg mice compared to the WT mice. Our data therefore confirm the findings of previous studies in which the secretion of TNF- $\alpha$ has also been found to be of importance for the host response to protect from the enhanced pneumococcal spread $[47,48]$.

It is also worth mentioning the significantly higher levels of the anti-inflammatory cytokine IL-10, detected in lung, BALF, and blood of IL-37tg mice. IL-10 has been shown to impair host defense in murine pneumococcal pneumonia, leading to an unimpeded spread of bacteria and increased mortality [49]. Furthermore, a mouse infection model with A. fumigatus showed increased IL-10 levels in lung tissue after treatment of WT mice with recombinant IL-37 [13]. Therefore, elevated IL-10 protein levels in the IL-37tg mice likely further intensifies the immunosuppressive effect of IL-37. Moreover, the fact that IL-10 enhanced the bacterial growth in human mononuclear phagocytes suggests that the increased IL-10 levels in IL-37tg mice might contribute to impairing the intracellular killing of S. pneumoniae in macrophages [50].

Neutrophils have been shown to be of critical importance for the control of pneumococcal infection [44]. Our data showed an up to $50 \%$ increase in the levels of the neutrophil chemoattractant (KC) and MCP-1 (CCL2) in the BALF and peripheral blood of the infected IL-37tg mice 24 and $48 \mathrm{~h}$ after infection. These cytokines induce activation, migration, and infiltration of macrophages and neutrophils into the lungs and activate neutrophils for increasing respiratory burst activity $[44,51]$. However, prolonged attraction of neutrophils, caused by enhanced levels of pulmonary chemokines, is a known risk factor for the development of acute lung injury through the release of oxidants and proteinases [52]. The overwhelming presence of neutrophils in the lungs of the IL$37 \mathrm{tg}$ mice are likely due to the increased KC and MCP-1 levels, thus triggering the massive inflammation in the surrounding lung tissue. This led to necrotizing pneumonia accompanied by disruption of the alveolar barrier and pulmonary edema. Furthermore, the uncontrolled growth of the pneumococci in the lungs of the IL-37tg mice despite a strong macrophage and neutrophil recruitment highlights the fact that the lungs must be cleared from the bacteria before their growth surpasses a threshold where even a strong inflammatory response will not be able to contain the infection.

An important feature of $S$. pneumoniae-induced lung infection is the TRAIL-induced apoptosis of AMs, which favors pneumococcal elimination and, additionally, limits overwhelming lung inflammation in response to infection [5]. At sites of inflammation, TRAIL has also been shown to induce apoptosis of neutrophils, which are then phagocytized by macrophages favoring the resolution of inflammation $[53,54]$. Remarkably, in the lungs of IL$37 \mathrm{tg}$ mice, we observed significant lower levels of TRAIL mRNA at $48 \mathrm{~h}$ after infection, despite increased alveolar recruitment of AMs and neutrophils, demonstrating that the initiation of the resolution phase of infection is affected by IL-37 expression. We further observed marked death and decay of neutrophils in the lungs of infected IL-37tg mice. Neutrophils were most likely recruited by the increased expression of chemokines and subsequently failed to undergo controlled cell death because of reduced TRAIL expression [54]. This cascade likely contributed to increased tissue damage and pneumococcal spread as well as the development of necrotizing pneumonia and increased mortality $[5,55]$.

Overall, it appears reasonable to assume that the interaction of pro- and anti-inflammatory immune responses during pneumococcal pneumonia must be tightly regulated to achieve a balance between effective pathogen elimination and limited damage to the lung parenchyma, to prevent a lethal outcome. Our data show that the powerful anti-inflammatory properties of IL-37 substantially impair the capability of mice to control pulmonary pneumococcal infection. IL-37 substantially modulates several core components of the initial host response to bacterial inoculation, thus permitting subsequent bacterial proliferation, recruitment of phagocytes into the lungs, and paradoxically increased pulmonary and systemic inflammation. This suggests that an initial intervention in the host defense against $S$. pneumoniae by suppressing pro-
416

J Innate Immun 2017;9:403-418 DOI: $10.1159 / 000469661$
Schauer et al. 
inflammatory cytokines through IL-37 is detrimental, causing an inflammatory event that and can no longer be controlled by the immune system during infection, leading to higher mortality rates. In conclusion, these data shed light on a potential unintended adverse effect that therapeutic approaches aiming to augment IL-37 function should be mindful of.

\section{Acknowledgement}

We thank Hester Bootsma, PhD (Laboratory of Pediatric Infectious Diseases Radboud University Nijmegen Medical Center, the Netherlands) for providing us the S. pneumoniae D39wt serotype 2 (encapsulated) and D39 $\Delta c p s$ (nonencapsulated mutant) strains.
The authors would like to acknowledge the excellent technical assistance provided by Simone Tänzer and Maximilian J. Lautenbach. Parts of this work will be included in the doctoral thesis of Anja E. Schauer.

This work was supported by the excellence graduate school Jena School for Microbial Communication (JSMC) funded by the Deutsche Forschungsgemeinschaft (H.S.). Furthermore, H.S. received grants from the Federal Ministry of Education and Research (BMBF), Germany, FZK 03Z2J521 ("MetaZIK”/ZIK Septomics Jena), and the Federal Ministry of Education and Research (BMBF), Germany, FZK 03Z2JN22. These studies were also supported by the National Institutes of Health (NIH) Grant AI 15614, the NIH Grant CA-04 6934 and the Interleukin Foundation (CAD), as well as the German Research Foundation (DFG) SFBTR 84 Z1b (to A.D.G.). The funders had no role in study design, data collection and analysis, decision to publish, or preparation of the manuscript.

\section{References}

1 O’Brien KL, Wolfson LJ, Watt JP, Henkle E, Deloria-Knoll M, McCall N, Lee E, Mulholland K, Levine OS, Cherian T; Hib and Pneumococcal Global Burden of Disease Study Team: Burden of disease caused by streptococcus pneumoniae in children younger than 5 years: global estimates. Lancet 2009;374: 893-902.

2 Torres A, Blasi F, Dartois N, Akova M: Which individuals are at increased risk of pneumococcal disease and why? Impact of COPD, asthma, smoking, diabetes, and/or chronic heart disease on community-acquired pneumonia and invasive pneumococcal disease. Thorax 2015;70:984-989.

3 Bhowmick R, Tin Maung NH, Hurley BP, Ghanem EB, Gronert K, McCormick BA, Leong JM: Systemic disease during streptococcus pneumoniae acute lung infection requires 12-lipoxygenase-dependent inflammation. J Immunol 2013;191:5115-5123.

4 Grommes J, Soehnlein O: Contribution of neutrophils to acute lung injury. Mol Med 2011;17:293-307.

5 Steinwede K, Henken S, Bohling J, Maus R, Ueberberg B, Brumshagen C, Brincks EL, Griffith TS, Welte T, Maus UA: TNF-related apoptosis-inducing ligand (TRAIL) exerts therapeutic efficacy for the treatment of pneumococcal pneumonia in mice. J Exp Med 2012;209:1937-1952.

6 Dinarello CA, Nold-Petry C, Nold M, Fujita M, Li S, Kim S, Bufler P: Suppression of innate inflammation and immunity by interleukin-37. Eur J Immunol 2016;46:1067-1081.

7 Nold MF, Nold-Petry CA, Zepp JA, Palmer BE, Bufler P, Dinarello CA: IL-37 is a fundamental inhibitor of innate immunity. Nat Immunol 2010;11:1014-1022.

8 Nold-Petry CA, Lo CY, Rudloff I, Elgass KD, Li S, Gantier MP, Lotz-Havla AS, Gersting SW, Cho SX, Lao JC, Ellisdon AM, Rotter B,
Azam T, Mangan NE, Rossello FJ, Whisstock JC, Bufler P, Garlanda C, Mantovani A, Dinarello CA, Nold MF: IL-37 requires the receptors IL-18Ra and IL-1R8 (SIGIRR) to carry out its multifaceted anti-inflammatory program upon innate signal transduction. Nat Immunol 2015;16:354-365.

9 Li S, Neff CP, Barber K, Hong J, Luo Y, Azam T, Palmer BE, Fujita M, Garlanda C, Mantovani A, Kim S, Dinarello CA: Extracellular forms of IL-37 inhibit innate inflammation in vitro and in vivo but require the IL-1 family decoy receptor IL-1R8. Proc Natl Acad Sci USA 2015;112:2497-2502.

10 Yousif NG, Li J, Yousif F, Ao L, Nold MF, Nold-Petry C, Fullerton DA: Expression of human interleukine-37 protects mouse heart against ischemic injury through suppression of monocyte chemoattractant protein-1-mediated mononuclear cell accumulation. Circulation 2011;124:Abstract 8603.

11 Davis CJ, Zielinski MR, Dunbrasky D, Taishi P, Dinarello CA, Krueger JM: Interleukin-37 expression in mice attenuates sleep responses to inflammation and influenza infection. Neurobiol Sleep Circadian Rhythms 2017;3:1-9.

12 Lunding L, Webering S, Vock C, Schroder A, Raedler D, Schaub B, Fehrenbach H, Wegmann M: IL-37 requires IL-18Ra and SIGIRR/ IL-1R8 to diminish allergic airway inflammation in mice. Allergy 2015;70:366-373.

13 Moretti S, Bozza S, Oikonomou V, Renga G, Casagrande A, Iannitti RG, Puccetti M, Garlanda C, Kim S, Li S, van de Veerdonk FL, Dinarello CA, Romani L: IL-37 inhibits inflammasome activation and disease severity in murine aspergillosis. PLoS Pathog 2014; 10:e1004462.

14 Ye L, Jiang B, Deng J, Du J, Xiong W, Guan Y, Wen Z, Huang K, Huang Z: IL-37 alleviates rheumatoid arthritis by suppressing IL-17 AND IL-17-triggering cytokine production and limiting Th17 cell proliferation. J Immunol 2015;194:5110-5119.

15 Weidlich S, Bulau AM, Schwerd T, Althans J, Kappler R, Koletzko S, Mayr D, Bufler P: Intestinal expression of the anti-inflammatory interleukin-1 homologue IL-37 in pediatric inflammatory bowel disease. J Pediatr Gastroenterol Nutr 2014;59:e18-e26.

16 Abbate A, Canada JM, Van Tassell BW, Wise CM, Dinarello CA: Interleukin-1 blockade in rheumatoid arthritis and heart failure: a missed opportunity? Int J Cardiol 2014; 171:e125-e126.

17 Di Stefano A, Caramori G, Barczyk A, Vicari C, Brun P, Zanini A, Cappello F, Garofano E, Padovani A, Contoli M, Casolari P, Durham AL, Chung KF, Barnes PJ, Papi A, Adcock I, Balbi B: Innate immunity but not NLRP3 inflammasome activation correlates with severity of stable COPD. Thorax 2014;69:516-524.

18 Kantso B, Simonsen J, Hoffmann S, Valentiner-Branth P, Petersen AM, Jess T: Inflammatory bowel disease patients are at increased risk of invasive pneumococcal disease: a nationwide Danish cohort study 1977-2013. Am J Gastroenterol 2015;110:1582-1587.

19 van de Veerdonk FL, Gresnigt MS, Oosting $M$, van der Meer JW, Joosten LA, Netea MG, Dinarello CA: Protective host defense against disseminated candidiasis is impaired in mice expressing human interleukin-37. Front Microbiol 2014;5:762.

20 Huang Z, Gao C, Chi X, Hu YW, Zheng L, Zeng T, Wang Q: IL-37 expression is upregulated in patients with tuberculosis and induces macrophages towards an M2-like phenotype. Scand J Immunol 2015;82:370-379.

21 Sharma S, Kulk N, Nold MF, Graf R, Kim SH, Reinhardt D, Dinarello CA, Bufler P: The IL-1 family member $7 \mathrm{~b}$ translocates to the nucleus and down-regulates proinflammatory cytokines. J Immunol 2008;180:5477-5482. 
22 Busfield SJ, Comrack CA, Yu G, Chickering TW, Smutko JS, Zhou H, Leiby KR, Holmgren LM, Gearing DP, Pan Y: Identification and gene organization of three novel members of the IL-1 family on human chromosome 2. Genomics 2000;66:213-216.

23 Ogunniyi AD, Giammarinaro P, Paton JC: The genes encoding virulence-associated proteins and the capsule of Streptococcus pneumoniae are upregulated and differentially expressed in vivo. Microbiology 2002;148: 2045-2053.

24 Hammerschmidt S, Wolff S, Hocke A, Rosseau S, Müller E, Rohde M: Illustration of pneumococcal polysaccharide capsule during adherence and invasion of epithelial cells. Infect Immun 2005;73:4653-4667.

25 Gutbier B, Fischer K, Doehn JM, von Lachner C, Herr C, Klaile E, Frischmann U, Singer BB, Riesbeck K, Zimmermann W, Suttorp N, Bachmann S, Bals R, Witzenrath M, Slevogt $\mathrm{H}$ : Moraxella catarrhalis induces an immune response in the murine lung that is independent of human CEACAM5 expression and long-term smoke exposure. Am J Physiol Lung Cell Mol Physiol 2015;309:L250-L261.

26 Reppe K, Radunzel P, Dietert K, Tschernig T, Wolff T, Hammerschmidt S, Gruber AD, Suttorp N, Witzenrath M: Pulmonary immunostimulation with MALP-2 in influenza virusinfected mice increased survival after pneumococcal superinfection. Infect Immun 2015; 83:4617-4629.

27 Klaile E, Klassert TE, Scheffrahn I, Muller MM, Heinrich A, Heyl KA, Dienemann H, Grunewald C, Bals R, Singer BB, Slevogt H: Carcinoembryonic antigen (CEA)-related cell adhesion molecules are co-expressed in the human lung and their expression can be modulated in bronchial epithelial cells by non-typable Haemophilus influenzae, Moraxella catarrhalis, TLR3, and type I and II interferons. Respir Res 2013;14:85.

28 Kadioglu A, De Filippo K, Bangert M, Fernandes VE, Richards L, Jones K, Andrew PW, Hogg N: The integrins Mac-1 and alpha4betal perform crucial roles in neutrophil and $t$ cell recruitment to lungs during streptococcus pneumoniae infection. J Immunol 2011; 186:5907-5915.

29 McNamee EN, Masterson JC, Jedlicka P, McManus M, Grenz A, Collins CB, Nold MF, Nold-Petry C, Bufler P, Dinarello CA, RiveraNieves J: Interleukin 37 expression protects mice from colitis. Proc Natl Acad Sci USA 2011;108:16711-16716.

30 Coll-Miro M, Francos-Quijorna I, SantosNogueira E, Torres-Espin A, Bufler P, Dinarello CA, Lopez-Vales R: Beneficial effects of IL-37 after spinal cord injury in mice. Proc Natl Acad Sci USA 2016;113:1411-1416.

31 Bufler P, Gamboni-Robertson F, Azam T, Kim SH, Dinarello CA: Interleukin-1 homologues IL-1f7b and IL-18 contain functional mRNA instability elements within the coding region responsive to lipopolysaccharide. Biochem J 2004;381:503-510.
32 Asokananthan N, Graham PT, Fink J, Knight DA, Bakker AJ, McWilliam AS, Thompson PJ, Stewart GA: Activation of protease-activated receptor (PAR)-1, PAR-2, and PAR-4 stimulates IL-6, IL-8, and prostaglandin E2 release from human respiratory epithelial cells. J Immunol 2002;168:3577-3585.

33 Mercer PF, Williams AE, Scotton CJ, Jose RJ, Sulikowski M, Moffatt JD, Murray LA, Chambers RC: Proteinase-activated receptor-1, CCL2, and CCL7 regulate acute neutrophilic lung inflammation. Am J Respir Cell Mol Biol 2014;50:144-157.

34 Moreland JG, Bailey G, Nauseef WM, Weiss JP: Organism-specific neutrophil-endothelial cell interactions in response to Escherichia coli, Streptococcus pneumoniae, and Staphylococcus aureus. J Immunol 2004;172:426-432.

35 Craig A, Mai J, Cai S, Jeyaseelan S: Neutrophil recruitment to the lungs during bacterial pneumonia. Infect Immun 2009;77:568-575.

36 Schwanhausser B, Busse D, Li N, Dittmar G, Schuchhardt J, Wolf J, Chen W, Selbach M: Global quantification of mammalian gene expression control. Nature 2011;473:337-342.

37 Sharova LV, Sharov AA, Nedorezov T, Piao Y, Shaik N, Ko MS: Database for mRNA half-life of 19977 genes obtained by DNA microarray analysis of pluripotent and differentiating mouse embryonic stem cells. DNA Res 2009; $16: 45-58$.

38 Eden E, Geva-Zatorsky N, Issaeva I, Cohen A, Dekel E, Danon T, Cohen L, Mayo A, Alon U: Proteome half-life dynamics in living human cells. Science 2011;331:764-768.

39 Yen HC, Xu Q, Chou DM, Zhao Z, Elledge SJ: Global protein stability profiling in mammalian cells. Science 2008;322:918-923.

40 Vernatter J, Pirofski LA: Current concepts in host-microbe interaction leading to pneumococcal pneumonia. Curr Opin Infect Dis 2013;26:277-283.

41 Dockrell DH, Marriott HM, Prince LR, Ridger VC, Ince PG, Hellewell PG, Whyte MK: Alveolar macrophage apoptosis contributes to pneumococcal clearance in a resolving model of pulmonary infection. J Immunol 2003;171: 5380-5388.

42 Hussell T, Bell TJ: Alveolar macrophages: plasticity in a tissue-specific context. Nat Rev Immunol 2014;14:81-93.

43 Tuomanen EI, Austrian R, Masure HR: Pathogenesis of pneumococcal infection. N Engl J Med 1995;332:1280-1284.

44 Calbo E, Alsina M, Rodriguez-Carballeira M, Lite J, Garau J: The impact of time on the systemic inflammatory response in pneumococcal pneumonia. Eur Respir J 2010;35:614618.

45 Fatykhova D, Rabes A, Machnik C, Guruprasad K, Pache F, Berg J, Toennies M, Bauer TT, Schneider P, Schimek M, Eggeling S, Mitchell TJ, Mitchell AM, Hilker R, Hain T, Suttorp N, Hippenstiel S, Hocke AC, Opitz B: Serotype 1 and 8 pneumococci evade sensing by inflammasomes in human lung tissue. PLoS One 2015;10:e0137108.
46 Witzenrath M, Pache F, Lorenz D, Koppe U, Gutbier B, Tabeling C, Reppe K, Meixenberger K, Dorhoi A, Ma J, Holmes A, Trendelenburg G, Heimesaat MM, Bereswill S, van der Linden M, Tschopp J, Mitchell TJ, Suttorp N, Opitz B: The NLRP3 inflammasome is differentially activated by pneumolysin variants and contributes to host defense in pneumococcal pneumonia. J Immunol 2011;187:434440.

47 Rijneveld AW, Florquin S, Branger J, Speelman P, Van Deventer SJ, van der Poll T: TNFalpha compensates for the impaired host defense of IL-1 type I receptor-deficient mice during pneumococcal pneumonia. J Immunol 2001;167:5240-5246.

48 Rijneveld AW, Florquin S, Speelman P, Edwards CK, Dinarello CA, van der Poll T: Interleukin-1 receptor antagonist transiently impairs antibacterial defense but not survival in murine pneumococcal pneumonia. Eur Cytokine Netw 2003;14:242-245.

49 van der Poll T, Marchant A, Keogh CV, Goldman M, Lowry SF: Interleukin-10 impairs host defense in murine pneumococcal pneumonia. J Infect Dis 1996;174:994-1000.

50 Park DR, Skerrett SJ: IL-10 enhances the growth of legionella pneumophila in human mononuclear phagocytes and reverses the protective effect of IFN-gamma: differential responses of blood monocytes and alveolar macrophages. J Immunol 1996; 157:25282538.

51 Deshmane SL, Kremlev S, Amini S, Sawaya BE: Monocyte chemoattractant protein-1 (MCP-1): an overview. J Interferon Cytokine Res 2009;29:313-326.

52 Dallaire F, Ouellet N, Bergeron Y, Turmel V, Gauthier MC, Simard M, Bergeron MG: Microbiological and inflammatory factors associated with the development of pneumococcal pneumonia. J Infect Dis 2001;184:292-300.

53 Renshaw SA, Parmar JS, Singleton V, Rowe SJ, Dockrell DH, Dower SK, Bingle CD, Chilvers ER, Whyte MK: Acceleration of human neutrophil apoptosis by TRAIL. J Immunol 2003; 170:1027-1033.

54 Beyer K, Poetschke C, Partecke LI, von Bernstorff W, Maier S, Broeker BM, Heidecke CD: TRAIL induces neutrophil apoptosis and dampens sepsis-induced organ injury in murine colon ascendens stent peritonitis. PLoS One 2014;9:e97451.

55 Cziupka K, Busemann A, Partecke LI, Potschke C, Rath M, Traeger T, Koerner P, von Bernstorff W, Kessler W, Diedrich S, Weiss FU, Maier S, Broker BM, Heidecke CD: Tumor necrosis factor-related apoptosis-inducing ligand (TRAIL) improves the innate immune response and enhances survival in murine polymicrobial sepsis. Crit Care Med 2010;38:2169-2174. 